MARTINS, L.S. et al. Composição tecidual de cortes da carcaça de cordeiros suplementados com ração contendo óleo de arroz. PUBVET, Londrina, V. 5, N. 3, Ed. 150, Art. 1006, 2011.

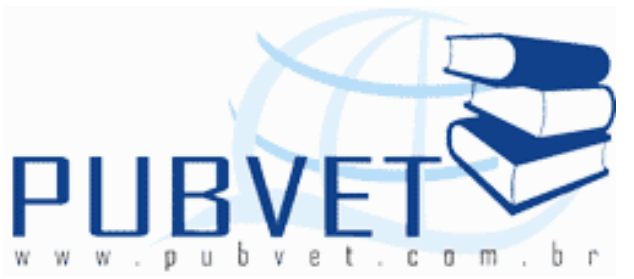

PUBVET, Publicações em Medicina Veterinária e Zootecnia.

\title{
Composição tecidual de cortes da carcaça de cordeiros suplementados com ração contendo óleo de arroz ${ }^{1}$
}

Luciane da Silva Martins², Maria Teresa Moreira Osório3 ${ }^{3}$, José Carlos da Silveira Osório ${ }^{3}$, Jaqueline Schneider Lemes ${ }^{4}$, Roger Marlon Gomes Esteves ${ }^{3}$, Rosilene Inês Lehmen ${ }^{5}$, Lucas Vargas Oliveira ${ }^{5}$

${ }^{1}$ Trabalho financiado pela FAPERGS e PROAP/CAPES

${ }^{2}$ Mestranda do Programa de Pós-Graduação em Zootecnia - UFPEL/RS. Bolsista CAPES

${ }^{3}$ Departamento de Zootecnia - FAEM - UFPEL/RS. Bolsista do CNPq

${ }^{4}$ Doutoranda do Programa de Pós-Graduação em Zootecnia - UFPEL/RS. Bolsista CAPES

${ }^{5}$ Graduando do Curso de Agronomia da UFPEL/RS. Bolsista PIBIC - CNPq

\section{Resumo}

O objetivo do estudo foi avaliar a composição tecidual da paleta e da perna de cordeiros tratados com ração padrão com ou sem adição de óleo de arroz. Foram utilizados 12 cordeiros machos, não castrados e não desmamados, obtidos pelo cruzamento das raças Corriedale e Lacaune, submetidos a dois tratamentos: ração padrão sem adição de óleo de arroz, com 3\% de extrato etéreo e ração padrão com adição de óleo de arroz, com 5\% de extrato etéreo. Os cordeiros foram sacrificados ao atingirem a condição corporal de 2,5 a 3 , em uma escala de 1 a 5, e apresentavam idade média de 90 dias. Realizou-se 
MARTINS, L.S. et al. Composição tecidual de cortes da carcaça de cordeiros suplementados com ração contendo óleo de arroz. PUBVET, Londrina, V. 5, N. 3, Ed. 150, Art. 1006, 2011.

a dissecção dos cortes para determinação da composição tecidual em gorduras, músculos e ossos. Não foi verificada diferença entre os componentes teciduais da paleta e da perna. Portanto, a adição de óleo de arroz não influenciou as características avaliadas.

Palavras-chave: extrato etéreo, gordura, músculo, osso

\title{
Tissue composition of cuts of the carcass of lambs supplemented with ration contend rice oil
}

\begin{abstract}
The objective of the study was to evaluate the tissue composition of shoulder and the leg of lambs dealt with ration standard with or without addition of rice oil. 12 male, not castrated and not weaned lambs had been used, gotten for the crossing of the races Corriedale and Lacaune, submitted the two treatments: ration standard without rice oil addition, with $3 \%$ of ether extract and ration standard with rice oil addition, $5 \%$ of ether extract. The lambs had been sacrificed when reaching the corporal condition of 2,5 the 3, in a scale of 1 the 5, and presented average age of 90 days. It was become fullfilled dissection of the cuts for determination of the tissue composition in fats, muscles and bones. Difference was not verified enters the tissues components of shoulder and the leg. Therefore, the rice oil addition did not influence the evaluated characteristics.
\end{abstract}

Keywords: ether extract, fat, muscle, bone

\section{Introdução}

O conhecimento da proporção e crescimento dos tecidos que compõem a carcaça são aspetos importantes na produção de carne ovina, orientando na produção de cordeiros que obtenham carcaças com alta proporção de músculo e adequada distribuição de gordura e, poder determinar a relação músculo:gordura que provoque mais alto grau de satisfação ao consumidor. 
MARTINS, L.S. et al. Composição tecidual de cortes da carcaça de cordeiros suplementados com ração contendo óleo de arroz. PUBVET, Londrina, V. 5, N. 3, Ed. 150, Art. 1006, 2011.

Sendo que, a alimentação é um fator que pode afetar a composição da carcaça. Segundo Pires et al. (2006), o balanceamento das dietas é uma das tecnologias empregadas para aumentar os índices de produtividade da ovinocultura, pois além de fornecer nutrientes em quantidades adequadas, possibilita ao produtor programar o tempo de abate dos seus animais e obter qualidade e padronização de carcaça.

Para Macedo et al. (2000) o uso de estratégias de suplementação alimentar tem sido adotado em oposição aos sistemas tradicionais de terminação a pasto, com o objetivo de diminuir a idade ao abate e melhorar a qualidade da carcaça.

Diante do exposto, objetivou-se estudar a composição tecidual da paleta e da perna de cordeiros tratados com ração padrão com ou sem adição de óleo de arroz.

\section{Material e Métodos}

O trabalho, na fase de campo, foi realizado no Centro Agropecuário da Palma, pertencente à Universidade Federal de Pelotas (UFPel), RS, e, na fase laboratorial, no Departamento de Zootecnia, FAEM/UFPel, utilizando-se 12 cordeiros machos não castrados (cruza Corriedale e Lacaune) e não desmamados, submetidos a dois tratamentos: ração padrão sem adição de óleo de arroz, com 3\% de extrato etéreo e ração padrão com adição de óleo de arroz, com $5 \%$ de extrato etéreo.

A base da alimentação foi a pastagem de azevém (Lolium multiflorum Lam), utilizando dois potreiros com área de 2,2 ha. O fornecimento da ração era feito uma vez ao dia, no período da manhã, a qual os cordeiros eram separados das mães para a suplementação em comedouros, sendo os mesmos divididos conforme os tratamentos. Amostras da ração comercial eram retiradas para a determinação do teor de matéria seca em estufa a $105^{\circ} \mathrm{C}$ (por 16 horas) e extrato etéreo em um extrator de gordura soxhlet (AOAC, 1995). Para obter uma ração com $5 \%$ de extrato etéreo a quantidade de óleo a ser adicionada foi calculada a partir da análise feita na ração comercial (padrão). 
MARTINS, L.S. et al. Composição tecidual de cortes da carcaça de cordeiros suplementados com ração contendo óleo de arroz. PUBVET, Londrina, V. 5, N. 3, Ed. 150, Art. 1006, 2011.

Os cordeiros foram sacrificados ao atingirem a condição corporal exigida no mercado, entre 2,5 e 3, em uma escala de 1 a 5 (Osório \& Osório, 2005), apresentando idade média de 90 dias. Previamente ao sacrifício os animais foram submetidos a jejum de 16 horas. Os animais foram sacrificados e as carcaças penduradas em câmara fria, permanecendo por 18 horas, sob temperatura média de $1^{\circ} \mathrm{C}$ com ar forçado. Depois, foram retiradas e divididas longitudinalmente em duas metades. A seguir, foi separada uma das metades em cortes, que foram congelados para avaliação da composição tecidual. As paletas e as pernas foram submetidas a descongelamento, sendo então pesadas e dissecadas em seus diferentes componentes teciduais: músculo, osso, gordura subcutânea, gordura intermuscular e outros tecidos. Cada tecido foi pesado e sua proporção calculada em relação ao corte.

O delineamento experimental foi o inteiramente casualizado com dois tratamentos (com ou sem adição de óleo de arroz na ração) e 6 repetições. Os dados foram submetidos à análise de variância através do programa Statistical Analysis System (SAS 2001).

\section{Resultados e Discussão}

Os resultados demonstram que não houve diferença $(P>0,05)$ entre os componentes teciduais da paleta de cordeiros alimentados com ração padrão com $3 \%$ ou $5 \%$ de extrato etéreo (Tabela 1 ). Os componentes teciduais apresentaram pesos superiores ao encontrado por Costa et al. (1999) para a raça Corriedale, no entanto, esses animais foram manejados em campo nativo, sem o fornecimento de ração.

Jardim (2005) encontrou percentuais semelhantes ao deste estudo trabalhando com cordeiros não castrados e castrados abatidos em diferentes idades, da raça Corriedale, alimentados exclusivamente a base de pastagem natural, porém com uma tendência a menores valores para músculo e outros tecidos, provavelmente explicado pela velocidade do crescimento muscular ser dependente do nível de consumo de energia. Já Pires et al. (1999), trabalhando com cordeiros cruza Texel x Ideal, alimentados em confinamento 
MARTINS, L.S. et al. Composição tecidual de cortes da carcaça de cordeiros suplementados com ração contendo óleo de arroz. PUBVET, Londrina, V. 5, N. 3, Ed. 150, Art. 1006, 2011.

e abatidos aos 100 dias, também encontrou valores semelhantes aos deste estudo, porém com tendência a maiores pesos para músculo e gordura provavelmente por influência do fator genótipo.

Tabela 1 - Médias e erro padrão da composição tecidual da paleta de cordeiros ( $\mathrm{kg} \mathrm{e} \%$ ) tratados com ração padrão com $3 \%$ e $5 \%$ de extrato etéreo.

\begin{tabular}{lccc}
\hline \multirow{2}{*}{ Parâmetros } & \multicolumn{2}{c}{ Extrato Etéreo } & P \\
\cline { 2 - 3 } & \multicolumn{2}{c}{$3 \%$} & $5 \%$ \\
\hline Paleta (kg) & $1,157 \pm 0,077$ & $1,208 \pm 0,080$ & 0,6410 \\
Osso (kg) & $0,244 \pm 0,017$ & $0,270 \pm 0,017$ & 0,2880 \\
Osso (\%) & $22,27 \pm 1,10$ & $22,34 \pm 0,61$ & 0,9484 \\
Músculo (kg) & $0,609 \pm 0,041$ & $0,633 \pm 0,041$ & 0,6840 \\
Músculo (\%) & $52,71 \pm 0,64$ & $52,49 \pm 1,74$ & 0,9065 \\
Gordura subcutânea (kg) & $0,104 \pm 0,016$ & $0,096 \pm 0,016$ & 0,7382 \\
Gordura subcutânea (\%) & $8,87 \pm 1,20$ & $8,07 \pm 1,40$ & 0,6717 \\
Gordura intermuscular (kg) & $0,059 \pm 0,009$ & $0,053 \pm 0,009$ & 0,6785 \\
Gordura intermuscular (\%) & $4,97 \pm 0,72$ & $4,35 \pm 0,44$ & 0,4840 \\
Outros tecidos (kg) & $0,141 \pm 0,017$ & $0,156 \pm 0,017$ & 0,5433 \\
Outros tecidos (\%) & $12,18 \pm 1,03$ & $12,74 \pm 1,01$ & 0,7051 \\
\hline
\end{tabular}

No que se refere a perna, também não foram encontradas diferenças na composição tecidual de cordeiros alimentados com ração padrão com 3\% ou $5 \%$ de extrato etéreo (Tabela 2). Osório et al. (2000) encontrou pesos inferiores para osso, músculo e gordura em cordeiros da raça Corriedale que embora tivessem idade superior aos animais deste estudo, 154 dias, foram criados exclusivamente a pasto o que parece ter influenciado a composição 
MARTINS, L.S. et al. Composição tecidual de cortes da carcaça de cordeiros suplementados com ração contendo óleo de arroz. PUBVET, Londrina, V. 5, N. 3, Ed. 150, Art. 1006, 2011.

tecidual dos cordeiros. Já Osório et al. (2002), trabalhando com cordeiros cruza Border Leicester com Corriedale criados em campo nativo e abatidos aos 6,5 meses de idade, verificaram valores próximos para osso e músculo, já para gordura subcutânea e gordura intermuscular encontraram valores superiores, salientando que esses autores trabalharam com animais mais velhos.

Tabela 2 - Médias e erro padrão da composição tecidual da perna de cordeiros ( $\mathrm{kg}$ e \%) tratados com ração padrão com 3\% e 5\% de extrato etéreo.

\begin{tabular}{lccc}
\hline \multirow{2}{*}{ Parâmetros } & \multicolumn{2}{c}{ Extrato Etéreo } & P \\
\cline { 2 - 3 } & \multicolumn{2}{c}{$3 \%$} & $5 \%$ \\
\hline Perna (kg) & $1,886 \pm 0,182$ & $1,972 \pm 0,067$ & 0,6656 \\
Osso (kg) & $0,391 \pm 0,039$ & $0,395 \pm 0,020$ & 0,9142 \\
Osso (\%) & $20,77 \pm 0,82$ & $20,04 \pm 0,67$ & 0,5013 \\
Músculo (kg) & $1,121 \pm 0,109$ & $1,183 \pm 0,047$ & 0,6118 \\
Músculo (\%) & $59,41 \pm 1,05$ & $59,95 \pm 0,90$ & 0,7007 \\
Gordura subcutânea (kg) & $0,070 \pm 0,013$ & $0,074 \pm 0,015$ & 0,8116 \\
Gordura subcutânea (\%) & $3,69 \pm 0,67$ & $3,75 \pm 0,72$ & 0,9510 \\
Gordura intermuscular (kg) & $0,092 \pm 0,014$ & $0,074 \pm 0,011$ & 0,3424 \\
Gordura intermuscular (\%) & $4,92 \pm 0,69$ & $3,75 \pm 0,58$ & 0,2220 \\
Outros tecidos (kg) & $0,213 \pm 0,027$ & $0,246 \pm 0,011$ & 0,2933 \\
Outros tecidos (\%) & $11,21 \pm 0,60$ & $12,51 \pm 0,66$ & 0,1773 \\
\hline
\end{tabular}

Não houve efeito das diferentes concentrações de extrato etéreo sobre a relação músculo:osso e músculo:gordura (Tabela 3). Jardim (2005), trabalhando com animais da raça Corriedale manejados em pastagem natural e 
MARTINS, L.S. et al. Composição tecidual de cortes da carcaça de cordeiros suplementados com ração contendo óleo de arroz. PUBVET, Londrina, V. 5, N. 3, Ed. 150, Art. 1006, 2011.

abatidos aos 120 dias de idade, obteve valores inferiores aos deste estudo para relação músculo:osso e músculo:gordura, tanto para paleta quanto para perna, provavelmente devido a variabilidade em quantidade e qualidade desse tipo de pastagem ao longo do ano.

Tabela 3 - Relação músculo:osso e músculo:gordura na paleta e perna de cordeiros tratados com ração padrão com 3\% e 5\% de extrato etéreo.

\begin{tabular}{lccc}
\hline & \multicolumn{2}{c}{ Extrato Etéreo } & \\
\cline { 2 - 3 } & $3 \%$ & $5 \%$ & $P$ \\
\hline Paleta & & \\
Músculo:osso & $2,49 \pm 0,09$ & $2,36 \pm 0,09$ & 0,3291 \\
Músculo:gordura & $3,98 \pm 0,47$ & $4,55 \pm 0,47$ & 0,4102 \\
Perna & & & \\
Músculo:osso & $2,89 \pm 0,15$ & $3,01 \pm 0,10$ & 0,5353 \\
Músculo:gordura & $7,35 \pm 0,78$ & $8,75 \pm 1,04$ & 0,3076 \\
\hline
\end{tabular}

Apesar de apresentar diferença na concentração de extrato etéreo entre os tratamentos, esta não foi suficiente para promover diferença na composição tecidual da paleta e da perna dos cordeiros. Certamente o critério de sacrifício dos animais, pela condição corporal e por haver alta relação entre a condição corporal e estado de engorduramento da carcaça (Osório et al., 2004; Esteves et al., 2010) e deste com a composição tecidual (Quadro et al. 2007), tenha sido fator de homogeneidade dos animais e sua composição tecidual.

\section{Conclusões}

Conclui-se que não há diferença nos componentes teciduais da paleta e da perna de cordeiros cruza da raça Corriedale e Lacaune, tratados com 
MARTINS, L.S. et al. Composição tecidual de cortes da carcaça de cordeiros suplementados com ração contendo óleo de arroz. PUBVET, Londrina, V. 5, N. 3, Ed. 150, Art. 1006, 2011.

suplemento de ração contendo óleo de arroz, quando os cordeiros são sacrificados a semelhante condição corporal.

\section{Agradecimentos}

A UFPEL e aos órgãos de fomento de pesquisa (FAPERGS, CNPq e CAPES) pelo apoio e financiamento para a realização do trabalho. A equipe do GOVI e ao Grupo de Carcaças e Carne por contribuir em todas as etapas do trabalho.

\section{Literatura citada}

ASSOCIATION OF OFFICIAL ANALYTICAL CHEMISTRY-AOAC. Official methods of analysis. 16.ed. Arlington: AOAC International, 1995. 1025p.

COSTA, J.C.C.; OSÓRIO, J.C.S.; OSÓRIO, M.T.M., et al. Composição regional e tecidual em cordeiros não castrados. Revista Brasileira de Agrociência, v.5, no 1, 50-53, jan.abril, 1999.

ESTEVES, R.M.; OSORIO, J.C.S; OSÓRIO, M.T.M; et al. Avaliação in vivo e da carcaça e fatores determinantes para o entendimento da cadeia da carne ovina. Revista Brasileira de Agrociência, Pelotas, v.16, n.1, p.-, 2010. Disponível em: http://www.ufpel.edu.br/faem/agrociencia/v16n1/artigo13.htm Acesso em: 07 de Out. 2010.

JARDIM, R.D. Composição tecidual da paleta e perna e química da carne de ovinos não castrados e castrados, abatidos em diferentes idades. Tese de doutorado. Universidade Federal de Pelotas. Pelotas-RS, Brasil, 89p., 2005.

MACEDO, F.A.F.; SIQUEIRA, E.R.; MARTINS, E. N. et al. Qualidade de carcaças de cordeiros Corriedale, Bergamácia x Corriedale e Hampshire Down x Corriedale, terminados em pastagem e confinamento. Revista Brasileira de Zootecnia, v.29, n.5, p.1520-1527, 2000.

OSÓRIO, J.C.S.; OLIVEIRA, N.M.; OSÓRIO, M.T.M.; et al. Efecto de la edad al sacrificio sobre la producción de carne en corderos no castrados de cuatro razas. Revista Brasileira de Agrociência, v.6 n.2, p.161-166, 2000.

OSÓRIO, J.C.S.; OLIVEIRA, N.M.; OSÓRIO, M.T.M.; et al. Produção de Carne em Cordeiros Cruza Border Leicester com Ovelhas Corriedale e Ideal. Revista Brasileira de Zootecnia, v.31 n.3, p.1469-1480, 2002 (supl.).

OSÓRIO, J.C.S.; CORREA, F.; OSÓRIO, M.T.M.; et al. Avaliação in vivo e da carcaça em cordeiros. In: CONGRESSO BRASILEIRO DE MEDICINA VETERINÁRIA, XXXIO, São Luís, Maranhão, p.1, CD, 2004.

OSÓRIO, J.C.S.; OSÓRIO, M.T.M. Produção de Carne Ovina: Técnicas de Avaliação "in vivo" e na carcaça. 2 ed., Pelotas, 2005, 82p. 
MARTINS, L.S. et al. Composição tecidual de cortes da carcaça de cordeiros suplementados com ração contendo óleo de arroz. PUBVET, Londrina, V. 5, N. 3, Ed. 150, Art. 1006, 2011.

PIRES, C.C.; CARVALHO, S.; GRANDI, A. et al. Características quantitativas e composição tecidual da carcaça de cordeiros terminados em confinamento. Ciência Rural, v.29 n.3, p.539-543, 1999.

PIRES, C.C.; GALVANI, D.B; CARVALHO, S. et al. Características da carcaça de cordeiros alimentados com dietas contendo diferentes níveis de fibra em detergente neutro. Revista Brasileira de Zootecnia, v.35 n.5, p.2058-2065, 2006.

QUADRO, J.L.G.; OSÓRIO, J.C.S.; OSÓRIO, M.T.M.; et al. Relação entre medidas in vivo e na carcaça em cordeiros Corriedale. Revista da FZVA, v.14, n.2, p.217-230. 2007

SAS Users's Guide, Statistics, Edition Cary, v. 8.2, NC, SAS INSTITUTE INC., 2001. 